\title{
A TRANSITORIEDADE NOS ESTADOS DE SAÚDE E DOENÇA: CONSTRUÇÃO DO COTIDIANO INDIVIDUAL E COLETIVO EM UMA COMUNIDADE RURAL
}

\author{
THE TRANSITORY STATES OF HEALTH AND DISEASE:THE CONSTRUCTION OF THE INDIVIDUAL \\ AND COLLECTIVE DAILY LIFE IN A RURAL COMMUNITY
}

\author{
Deise Lisboa Riquinho ${ }^{1}$ \\ Tatiana Engel Gerhardt ${ }^{2}$
}

Resumo O objetivo deste artigo é o de conhecer e compreender as necessidades em saúde, por meio da autopercepção do estado de saúde e doença, considerando as desigualdades sociais presentes na localidade rural de Rincão dos Maia, Canguçu, Rio Grande do Sul. Utilizou-se a triangulação de métodos. No desenho qualitativo entrevistaram-se vinte sujeitos. A amostra foi intencional, ilustrativa das diferentes situações de vida, e a análise, temática. Os resultados indicaram que a sensação de estar adoecido é fortemente vinculada ao modo como se vivencia essa enfermidade, tendo em vista a incapacidade que este estado impõe, seja ela física ou mental. A alternância entre sentir-se doente ou saudável vem da constatação prática de que nenhum estado é contínuo. A observação do meio natural sinaliza o quão tênue são os estados de saúde e doença. A 'situação de vida', elaborada a partir das condições de vida e mobilização de recursos sociais, demonstrou que, apesar das diferenças econômicas, esse grupo apresentava uma coesão social, especialmente em sua matriz cultural de trabalhadores rurais. Enfatiza-se, assim, a necessidade de considerar o significado do fenômeno saúde e doença como ferramenta imprescindível para a formulação de programas de promoção e prevenção à saúde da população rural.

Palavras-chave saúde da população rural; saúde pública; desigualdade social; condições de saúde.
Abstract The aim of this article is to get to know and understand the health needs, through one's self-perception of the state of health and disease, considering the social inequalities there are in the rural town of Rincão dos Maia, Canguçu, Rio Grande do Sul. The method triangulation approach was used. Twenty subjects were interviewed in the qualitative design. The sample was intentional, illustrative of the different life situations, and the analysis was thematic. The results indicated that the feeling of being ill is strongly tied to how one experiences the disease, in view of the inability this state brings about, whether physical or mental. Alternating between feeling sick or healthy comes from the practical verification of the fact that no state is continuous. Observing the natural environment signals just how tenuous the states of health and disease in fact are. The 'life situation,' compiled based on the living conditions and on the mobilization of social resources, showed that despite the economic differences, this group was socially cohese, especially in its farmer cultural matrix. The need to consider the meaning of the health and disease phenomenon as an indispensable tool to formulate health prevention and promotion programs for the rural population is therefore emphasized.

Keywords rural population health; public health; social inequality; health conditions. 


\section{Introdução}

A aproximação dos processos de saúde e doença vivenciados pelas pessoas por meio do saber-fazer em seu cotidiano é um diálogo necessário de ser realizado por pesquisadores e profissionais de saúde (Soares e Camargo Jr., 2007; Favoreto e Cabral, 2009). É no cotidiano que a vida acontece, nessa arena ocorrem contínuos processos de negociação, resistência e sentido. Segundo Heller (2009), faz parte do cotidiano o trabalho, a vida privada, o lazer, o descanso e as atividades sociais; as escolhas realizadas pelos sujeitos decorrem dessas vivências concretas, assim como do compromisso pessoal e moral. Estes compromissos são marcados por processos transitórios vividos no cotidiano e pelas transformações complexas das relações sociais.

Os determinantes sociais de saúde (DSS) colaboram e definem as condições concretas em que as pessoas vivem e trabalham, representando as características específicas do contexto social que podem afetar a saúde, bem como a maneira com que as condições sociais traduzem esse impacto (Comission on social..., 2005).

As condições de vida abarcam os aspectos referentes às circunstâncias materiais e imateriais: as primeiras, pelas condições de subsistência, moradia, trabalho, meio ambiente e produção; as segundas referem-se a valores, crenças e representações. Esse sistema não é estático, o material é modelado pelo imaterial e vice-versa, num sistema circular (Raynaut, 2006). Tal interação é visualizada a partir da constatação das condições de vida de um indivíduo e da maneira como as representações construídas direcionam suas ações. É o que leva uma pessoa a adquirir um eletrodoméstico, por exemplo, uma geladeira, mesmo que ela passe a maior parte do tempo desligada, por não haver alimentos para guardar no seu interior. Na situação inversa, ao apresentar um problema de saúde (uma dimensão do real), o indivíduo busca explicações, além das científicas, utilizando-se de percepções e conhecimento que deem sentido a sua experiência, neste caso o adoecimento.

As concepções de saúde ocorrem de forma diferente para as pessoas, conforme o modo de vida, os aspectos sociais, econômicos e culturais. Para Helman (2003), a saúde, na maioria dos casos, está para além da ausência de sintomas orgânicos desagradáveis; relaciona-se a aspectos físicos, psicológicos e comportamentais. Compreender tais concepções é uma aproximação das necessidades de saúde e poderá colaborar para o processo de interação entre equipe de saúde e usuários.

A compreensão das necessidades de saúde deve levar em conta a pluralidade dos espaços nos quais as pessoas vivem, bem como contemplar a diversidade de escolhas dos indivíduos. Segundo Stotz (1991), as necessidades de saúde configuram-se como categorias sociais e são construídas historicamente. 
Ao considerá-las como uma construção histórica, recorre-se à VIII Conferência Nacional de Saúde brasileira, realizada no ano de 1986, mediante a participação de profissionais, usuários e gestores, na qual se definiu o que é saúde:

Em seu sentido mais abrangente, a saúde é o resultado das condições de alimentação, habitação, educação, renda, meio-ambiente, trabalho, transporte, emprego, lazer, liberdade, acesso e posse da terra e acesso a serviços de saúde. É ainda, antes de tudo, o resultado das formas de organização social da produção, as quais podem gerar grande desigualdade nos níveis de vida (Conselho Nacional de Saúde, 1986, p. 12).

Apesar de ser um conceito amplo, sua aplicabilidade ainda é um desafio, pois o modelo de sociedade capitalista no qual se vive impõe desafios ao acesso à alimentação, habitação, organização social e aos demais elementos que colaboram para boas condições de vida. Outro fator é a preponderância na visão da saúde do modelo médico hegemônico, no qual a dimensão biológica é supervalorizada, em detrimento das dimensões subjetivas.

Melo (2005), ao contribuir para uma concepção ampliada de saúde, complementa que ela pode ser entendida como um direito social, ultrapassando as ações específicas de promoção, prevenção, reabilitação e recuperação, pois sua determinação envolve as condições de vida, de trabalho, ambientais, emocionais, bem como as demais necessárias ao prosseguimento da vida com um mínimo de qualidade.

A noção do cuidado em saúde requer essa dimensão ampliada da compreensão das condições de vida, considerando a individualidade dos atores, sem perder de vista o coletivo, o meio social em que vivem e se identificam. Ao analisar as percepções e a participação de usuárias de unidade básica de saúde em relação à prevenção e promoção de saúde, Figueira et al. (2009) observaram que o discurso das entrevistadas alia as concepções presentes na prática hegemônica de saúde com o conceito positivo de saúde, privilegiando o bem-estar, o prazer e a força de vontade como principais influenciadores do comportamento.

Essa consideração leva ao entendimento de que saúde e doença possuem dimensões objetivas e subjetivas: como objetiva, pode-se citar, por exemplo, os parâmetros do exame físico ou laboratorial; e como subjetiva, as experiências e percepções que as pessoas construíram individual ou coletivamente (Souza, 2005). Trata-se de considerar que essas dimensões interagem constantemente. Ayres (2007) complementa essa ideia, exemplificando que o estar ou sentir-se saudável não consiste, necessariamente, na presença ou ausência de uma doença; é possível que uma pessoa portadora de uma enfermidade, ao ser questionada se se sente saudável, diga que sim, enquanto outra, mesmo que não possua qualquer enfermidade, diga não se sentir saudável. 
Nesse sentido, o objetivo desta pesquisa é o de conhecer e compreender as necessidades em saúde, por meio das concepções do estado de saúde e doença, considerando as desigualdades sociais presentes na localidade rural de Rincão dos Maia, Canguçu, Rio Grande do Sul.

\section{Percurso metodológico}

As considerações precedentes indicam a correlação complexa entre as condições de vida e saúde da população, reunindo as dimensões objetivas, subjetivas, individuais e coletivas. Apresenta-se o contexto e a problemática da área empírica para uma aproximação dos aspectos relacionados às relações sociais, organização econômica e cultural, com o intuito de enfocar as especificidades da população estudada.

\section{Histórico e características locais: o município de Canguçu e a localidade de Rincão dos Maia}

O município de Canguçu situa-se na 'metade sul' do estado do Rio Grande do Sul, na Serra do Sudeste. A população total é de 51.427 habitantes, dos quais $17.685(34,40 \%)$ residem na zona urbana, e $33.742(65,60 \%)$ residem nas áreas rurais, que se dividem em cinco distritos e 120 localidades (IBGE, 2000).

Rincão dos Maia localiza-se no primeiro distrito do município, distante $12 \mathrm{~km}$ da sede, aproximadamente. Nessa localidade concentra-se o maior número de pequenos estabelecimentos familiares do município; em média, a área total está entre sete e dez hectares; as famílias de agricultores dedicamse ao cultivo da matéria-prima direcionada à indústria de doces e conservas ou às empresas de tabaco.

A condição de vida no Rincão dos Maia, no passado, era precária, com famílias numerosas, atividade agrícola incipiente e casas de pau-a-pique, chão batido (terra) e cobertas com capim santa-fé (palha) ou telhas sem forro; a cada chuva eram novamente rebocadas de barro, a pobreza era generalizada. As pessoas eram reconhecidas facilmente pelos moradores da cidade ou de outras localidades, pelo tipo físico (subnutridos), pela forma de vestir, pelos gestos e pela fala; tidos como violentos e brigões, a localidade tinha o apelido de 'rincão do pulguedo' (Fialho, 2005).

No fim da década de 1970 e início de de 1980, houve a aplicação do Programa de Desenvolvimento de Comunidade pela Superintendência do Desenvolvimento da Região Sul (Sudesul), que, após diagnóstico da Universidade Católica de Pelotas, evidenciou as precárias condições de vida e restrições econômicas e sociais das famílias daquela localidade. As intervenções ti- 
nham como foco modificações no plantio e conservação do solo, por meio da diversificação, fertilização, diminuição das queimadas, aquisição de equipamentos agrícolas e melhoria do saneamento, com a construção de fossas sanitárias (Fialho, 2005). No entanto, as estratégias de desenvolvimento não atingiram todos os moradores. As condições de moradia e a atividade produtiva pouco mudaram no decorrer dos anos.

A localidade dispõe de uma escola municipal de ensino fundamental completo, um posto de saúde, com atendimento duas vezes na semana, por um técnico de enfermagem, e quinzenal, por médico e odontólogo. A demanda é espontânea, e as atividades, mais destinadas aos usuários com diabetes e hipertensão. Mensalmente há encontro para distribuição de medicação e orientações pelo técnico de enfermagem. Em caso de problemas de saúde agudos ou crises recorrentes, as pessoas procuram atendimento na cidade, pois é comum, nos dias previstos, não haver atendimento.

Atualmente, a população é estimada em 300 famílias; destas, 241 fizeram parte do estudo, perfazendo um total de 814 pessoas, que apresentavam as seguintes características sociodemográficas: $51,2 \%$ são do sexo masculino; $48,0 \%$ pertencem ao grupo etário de 25-59 anos de idade; $42,6 \%$ possuem escolaridade de um a quatro anos de estudo; 45,0\% são agricultores; e 48,5\% das famílias têm composição nuclear. Em relação à morbidade, 63,6\% referiram pressão alta e 59,6\%, depressão. Quanto aos fatores socioeconômicos, $91,2 \%$ das habitações são de alvenaria e 56,0\% sem piso e/ou forro; $65,0 \%$ dispõem de sanitário; $52,7 \%$ plantam para comercialização e subsistência; e 71,8\% utilizam ônibus ou moto como transporte.

As condições de vida das famílias estudadas foram descritas em três diferentes níveis, assim distribuídos: inferior, 84 famílias (34,8\%); médio, 103 famílias (42,7\%); e superior, 54 famílias (22,4\%). As variáveis definidoras foram as condições da habitação, presença de sanitário, tipo de produção e transporte mais utilizado.

Algumas características são marcadamente diferentes quando analisadas pelas condições de vida, em especial nos extremos, na condição de nível inferior e superior; na condição de nível médio, algumas características aproximam-se mais do inferior e ora do superior. Na condição de vida inferior, a ocupação predominante é a de agricultor diarista, compreendendo aquele que planta para subsistência, mas o ganho monetário ocorre trabalhando em outras propriedades. A justificativa possível desse quadro advém dos altos investimentos em insumos e das perdas crescentes na lavoura; consequentemente, o tipo de produção se concentra na subsistência (Schneider e Fialho, 2000). Quanto à morbidade, os denominados 'sofrimentos difusos' foram os mais referidos (Valla, 2005). As habitações sem piso e/ou sem forro representaram 95,2\% dos domicílios, e sem sanitário, $81 \%$, considerando que se trata de uma região serrana, o inverno é frio e úmido, expondo assim seus 
moradores a essas alterações climáticas. Os meios de transporte mais utilizados são motos ou ônibus. As motos, em sua maioria, estão com documentação irregular, impedindo que circulem na cidade, e o ônibus está disponível aos moradores três vezes na semana e durante o dia. Quando precisam ir até a cidade em dias e horários diferentes, vão a pé ou pagam a algum vizinho por esse serviço. Essa realidade é comum na condição de vida inferior e média.

(...) e daí a minha irmã tinha consulta 1 lá no tal de Caps, aquele, e é longe, não tinha ônibus para a gente ir, nós saímos às $6 \mathrm{~h}$ de a pé, para não pegar sol e para arrumar algum papel, nós saímos daqui às 6h da manhã, eu e ela (F160, SV médio).

Na condição de vida superior há mais pessoas com escolaridade entre nove e 11 anos de estudo, possivelmente devido à necessidade de sair da localidade para estudar e à dificuldade de pagamento de transporte. A ocupação é agricultor, e o tipo de produção, para comercialização e subsistência. Problemas cardiovasculares são a morbidade referida, igualmente para a condição de vida média, indicando possivelmente a maior facilidade de acesso aos serviços de saúde e a diagnóstico (Viacava, 2002). Neste nível não há moradia sem piso e/ou forro, sendo que 90,7\% delas apresentam boas condições e em $98,1 \%$ há sanitário. O transporte mais utilizado é automóvel e/ou caminhão.

Diante das desigualdades presentes nas condições de vida e saúde, a mobilização de recursos sociais configura-se como uma estratégia fundamental na resolução dos problemas cotidianos, contribuindo para a manutenção das necessidades básicas, como saúde, alimentação, higiene, habitação e fortalecendo os grupos sociais aos quais pertencem e com os quais possuem uma identidade.

As famílias extensas são exemplo de apoio intrageracional, assim como a ocupação de agricultor e comerciante, ou ainda ter nascido na localidade ou morar há mais de cinco anos. Tais características podem favorecer a entreajuda, fortalecendo as redes de apoio social e amenizando os efeitos da exclusão econômica (Gerhardt, 2000).

Em relação à mobilização de recursos sociais, as famílias ficaram distribuídas em três níveis: I (fraco) 39,4\%, II (médio) 25,3\% e III (forte) 35,3\%. As famílias extensas estão mais presentes nas condições de vida de tipo superior, e as nucleares, nas condições de vida de tipo médio, enquanto as monoparentais nas condições de tipo inferior. No caso das famílias monoparentais, a ausência de um dos cônjuges e a idade avançada dificultariam a autonomia na atividade de agricultor, sendo então preterida pela de agricultor diarista, do lar ou mesmo diarista. Hipoteticamente as famílias que têm piores condições de vida mobilizam menos recursos sociais. 
No entanto, as relações sociais não são estáticas e a conformação de rede pode ocorrer de forma distinta conforme as necessidades sentidas em cada momento da vida. O conceito adotado de situação de vida visa a dar conta dessa realidade dinâmica, em que as condições de vida são traduzidas pelos recursos materiais, e a mobilização de recursos sociais acontece na interação das condições materiais e imateriais, do real e do simbólico, no qual as percepções externalizadas exprimem essa relação.

A partir dos diferentes níveis de mobilização de recursos sociais e condições de vida, elaborou-se a tipologia de 'situação de vida' (SV). O tipo 1, SV inferior, representa 40,7\% das famílias entrevistadas, situação de vida prejudicada, tendo em vista as condições de vida piores e menor mobilização de recursos sociais. No tipo 2, SV médio, em 25,7\% das famílias estudadas, as condições de vida são remediadas por certa possibilidade de mobilização de recursos sociais. Quanto ao tipo 3, SV superior, 33,6\% das famílias apresentam melhores condições de vida e possibilidade de mobilização de recursos sociais.

\section{As etapas da pesquisa: coleta e análise dos dados}

Na tentativa de uma aproximação com a dinâmica de vida das pessoas da localidade, desenvolveu-se o estudo por meio de uma abordagem de triangulação de métodos. Segundo Minayo (2005), essa abordagem significa a combinação e o cruzamento de múltiplos pontos de vista, numa tarefa conjunta de pesquisadores e no emprego de uma variedade de técnicas de coleta de dados que acompanha o trabalho de investigação. A triangulação de métodos valoriza a quantificação como parte da qualidade dos fenômenos e dos sujeitos sociais, marcados por estruturas, relações e subjetividade. As informações qualitativas, por sua vez, situam a realidade, cujos fenômenos podem ser explicados em sua magnitude e compreendidos em sua intensidade, aprofundando as reflexões em suas múltiplas dimensões (Minayo, 2005).

No desenho qualitativo que é explorado neste artigo, entrevistaram-se 20 indivíduos, correspondendo a 20 famílias, sendo que a escolha dos entrevistados ocorreu conforme a disponibilidade em participar. Em todas as entrevistas, mais de um membro da família estava presente. O critério de saturação dos dados foi utilizado para a limitação do número de entrevistados (Ghiglione e Matalon, 1997). A seleção da amostra realizou-se de forma intencional, visando a obter um número de famílias ilustrativas das diferentes 'situações de vida'.

Nessa etapa da pesquisa, exploraram-se as concepções do estado de saúde e doença por meio de um guia de entrevistas semiestruturadas. Considera-se que as concepções vinculam-se à subjetividade, referindo-se a construções sociais para explicar fenômenos e processos (Minayo, 2007). Em todas as 
etapas utilizaram-se anotações em diário de campo. A coleta de dados aconteceu durante três meses: fevereiro, março e junho de 2008. A análise ocorreu por categorização temática (Minayo, 2007).

Em relação às considerações éticas, todos os participantes receberam o consentimento livre e esclarecido, e o projeto de pesquisa foi submetido e aprovado pelo Comitê de Ética da Universidade do Rio Grande do Sul, em reunião de $n .{ }^{\circ} 2$, ata $n .{ }^{\circ} 82$, de $1 / 3 / 2007$.

A apresentação e a análise dos depoimentos sobre a doença são identificadas por família (F) e o número se refere à ordem das famílias entrevistadas na fase quantitativa, seguida da SV. Parte-se do pressuposto de que dar voz a essas pessoas permite a aproximação de suas necessidades de saúde, através da compreensão das percepções dos processos vividos.

\section{Resultados e discussão}

As concepções de saúde das famílias do Rincão dos Maia foram divididas em três subcategorias: saudável, adoecido e alternância de estado. Os entrevistados se referem à saúde, apesar da presença de uma doença ou enfermidade, desde que mantenha sua capacidade para o trabalho. O sentimento de estar adoecido vem das limitações sociais e físicas imposta pela doença. A alternância de estado surge da percepção da instabilidade entre sentir-se saudável ou adoecido. Assim, concorda-se com Dejours (1986) quando diz que a noção de saúde passa por experiências pessoais, na direção do bemestar físico, psíquico e social. Portanto, a aproximação das necessidades de saúde ocorre por meio do conhecimento do que significa saúde e doença para as pessoas, e esse significado será diferente em função de suas experiências de vida e interação com o coletivo.

\section{Saudável: "tive meus problemas, mas me considero muito saudável”}

Nesta subcategoria as falas referem-se ao desejo de estar bem, sentir-se bem, estar com saúde; mesmo na presença de enfermidade, saúde e doença parecem estados transitórios:

O meu negócio é esse açúcar que eu tenho no sangue que me estorva, demais; eu sou sadia, graças a Deus (F22, SV inferior).

Até que me considero com saúde; em vista de muitas pessoas que têm o mesmo problema que eu (diabetes e hipertensão), eu me considero com saúde ainda (F03, SV médio). 
Apesar dos problemas ou mesmo na presença de uma doença crônica, como diabetes e hipertensão, sentem-se bem e ainda com saúde, assim acentuam a dimensão subjetiva de quem vive esses processos, sem negá-los, mas reconhecendo que mesmo na presença de uma enfermidade é possível ser saudável.

Em um estudo em nível nacional, cuja abordagem centrava-se na presença de doença de longa duração ou incapacitante e a autoavaliação da saúde, os resultados apontaram que pessoas portadoras de doenças crônicas não se percebiam como doentes (Theme Filha; Szwarcwald; Souza Júnior, 2008).

Tais informações constituem-se relevantes aos profissionais de saúde que atendem pessoas portadoras de doenças crônicas, pois essa percepção precisa ser considerada nas orientações e no acompanhamento, para que não prejudique a adesão ao tratamento característico dessas patologias.

Para Herzlich (2004), as experiências relativas à saúde e à doença são individuais, porém tornam-se socializadas por meio do convívio. Nesse sentido, as pessoas que convivem com doenças crônicas estão se manifestando e usando suas experiências como argumentos a serem considerados na elaboração de políticas, uma vez que doenças de longa duração afetam múltiplos aspectos da vida do seu portador, diferindo dos modelos de cuidados de saúde centrados na doença aguda (Herzlich, 2004).

Os relatos apresentados denotam um desejo de 'seguir em frente'; mesmo com a presença de uma patologia, consideram-se com saúde. Segundo Ayres (2007), falar sobre saúde não equivale a falar sobre não-doença e falar sobre doença não equivale a falar sobre não-saúde. A saúde é reconhecida e reconstruída na esfera prática da vida. A experiência da saúde envolve a construção compartilhada de ideias de bem-viver, de um modo de buscar realizá-las na vida (Ayres, 2007).

A ideia do bem-viver é revelada por meio do trabalho de forma recorrente, como no depoimento a seguir:

Felizmente uma vez que eu esteja trabalhando, esteja bem, assim eu tô bem de saúde, graças a Deus (F120, SV inferior).

Observa-se que, desde que tenha força para o trabalho, esteja trabalhando, considera-se com boa saúde. Nesse sentido, estar com saúde é o mesmo que ter condições de trabalho, constituindo-se um elemento de extrema significância no processo de formação de consciência, enquanto ser e estar no mundo (Hegel, 1992).

Dessa forma, é por meio do trabalho que algumas relações se estabelecem, em especial no meio rural, em que as pessoas estão submetidas ao intenso uso do corpo e à manutenção da saúde, expressa em uma relação praticamente direta com essa atividade (Dias et al., 2007). 
O trabalho acrescenta um sentimento durável à vida, assim como contribui para manutenção das engrenagens socioeconômicas por vezes tão impiedosas quanto os processos biológicos (Arendt, 2008).

A autopercepção em sentir-se saudável, apesar de problemas por doenças crônicas ou enquanto se trabalha, compõe processos interpretativos que elucidam os significados do adoecer para cada indivíduo, bem como a interação com seu contexto de vida, em que a intersubjetividade retroalimenta esses processos (Ayres, 2002).

\section{Adoecido:"agora eu me considero doente, porque eu mudei a minha vida"}

A presença da diminuição da capacidade física e social colabora para a sensação de deficiência, não somente para a pessoa que experiencia a doença como também para as que estão ao seu redor; o sofrimento físico produz efeito emocional, refletindo na vida a desorganização do corpo (Corbin, 2003).

Nesse sentido, a pessoa expressa as mudanças sofridas no corpo por meio de sensações apoiadas em experiências no mundo social, as quais comumente não são descritas por sintomas, mas por alterações de sensações como, "dificuldade de subir escadas" ou "não se sentir bem" (Corbin, 2003).

Essas expressões das sensações impostas ao corpo adoecido compreendem aspectos relevantes para o estudo de saúde e doença, como observado:

Agora eu considero que sou doente, porque eu mudei a minha vida, do jeito que eu era, eu mudei, porque a pessoa sadia é de um jeito, e a pessoa doente já é de outro jeito. Eu trabalhei muito e, antes de fazer essa segunda cirurgia, eu ainda trabalhava, estava bem, agora mudei a minha vida, pra mim não tinha sol, não tinha chuva, não tinha nada, eu mudei a minha vida. Barbaridade! O jeito que eu era pro jeito que eu fiquei, Deus o livre, eu trabalhava na fábrica de compotas (de doce), chegava às vezes dez ou 11 horas da noite, fazia meu serviço de casa e no outro dia bem cedo estava pronta para ir (à fábrica), agora nem comida posso fazer, se não é ele (filho), é o marido que tem que fazer (F165, SV médio).

As mudanças ocorridas fazem com que se considere doente, a justificativa vem da sua história de adoecimento: “a pessoa sadia é de um jeito e a doente de outro". A doente tem restrição de atividades; quando sadia, ela afirma que não havia sol, não havia chuva, desempenhava uma dupla jornada de trabalho, na fábrica de compotas e em casa. No entanto, agora nem comida pode fazer, depende do filho ou do marido. Nesse depoimento chama a atenção o fato da autoculpabilização, em que a entrevistada diz "eu mudei a minha vida", como se ser acometida por uma doença fosse sua culpa. 
A doença percebida como um castigo divino, uma penalidade por erros cometidos é citada por autores como Minayo (2007) e Helman (2003), e muitas vezes reforçada nos discursos biomédicos em que as pessoas são responsáveis por sua saúde, devendo adotar um estilo de vida saudável e procurar regularmente os serviços de saúde.

$\mathrm{Na}$ experiência de adoecer, especialmente no caso de episódios graves ou incapacitantes, aparece nas falas uma divisão entre corpo e mente das pessoas doentes, há uma diferenciação do self e do corpo; enquanto um formula, deseja e lembra, o outro não mais executa (Corbin, 2003). Dessa forma, segundo o mesmo autor, a doença intromete-se na vida, perturbando o tempo biográfico, com o corpo do presente e do futuro sendo comparado ao corpo do passado, muitas vezes resultando em um profundo sentimento de perda e mudança de identidade.

Assim, observa-se no próximo depoimento que o papel social de mãe exige o desempenho de tarefas às quais a entrevistada não se julgava capaz:

Eu me achava muito prejudicada, não tinha força para lidar com os filhos e os filhos precisavam de mim, eles eram doentes, precisavam da mãe para cuidar deles, dar comidinha pra eles, lavar a roupinha deles (...) (F68, SV inferior).

Nesse caso, a entrevistada relata que se achava muito prejudicada, os filhos precisavam dela, pois eram doentes, necessitavam de cuidados, alimentação e roupas limpas, mas ela também precisava receber cuidados; sozinha, não tinha força para realizar tais tarefas.

Segundo Corbin (2003), a construção da identidade da doença advém do temor de que se está perdendo o controle sobre o corpo ou que se está 'deixando de fazer' o que antes não havia impedimento em fazer.

Dessa maneira, a doença interfere no modo de vida das mulheres acometidas, modificando sua subjetividade, rede de sociabilidade e autonomia de ação, provocando, assim, sofrimento pela não correspondência aos padrões sociais esperados no desempenho da maternidade (Adorno et al., 1994).

A ideia da doença como privação é apresentada em muito dos depoimentos; o próximo refere-se à diminuição das liberdades em escolher os alimentos que serão ingeridos:

Ah, porque a pessoa com saúde faz tudo, né? Até na comida, ela tem liberdade de comer tudo, e quem tem doença, não. Principalmente eu mesmo, tem muitas coisas que eu tenho de evitar comer, eu tenho açúcar no sangue, tenho problema de angina no peito, de pressão alta e as minhas varizes que incomodam (F03, médio).

Novamente retorna a diferenciação entre quem tem saúde e quem não a tem; nesse caso, a entrevistada afirma que a pessoa com saúde faz tudo, tem 
liberdade para escolher o que irá comer, já quem tem uma doença, como, por exemplo, o diabetes, precisa evitar alguns alimentos.

Barsaglini (2007) evidenciou, ao pesquisar a experiência da enfermidade entre pessoas com diabetes tipo 2, certa desconfiança em relação ao valor nutricional e a restrição alimentar, com o argumento de que existem poucas opções alimentares. Nesse sentido, segundo Boltanski (1989), dentre os alimentos valorizados pelas classes trabalhadoras estão aqueles ricos em carboidratos e gorduras, os quais, além do teor energético, possuem um valor simbólico em prover a recuperação e manter a força física. Portanto, tais escolhas alimentares relacionam-se às concepções de saúde, em que ter saúde é ter força para trabalhar.

Nesse sentido, a doença revela um pouco da impotência perante a vida, que poderá agravar-se com o passar dos anos, como relatado a seguir:

Eu me considero doente, isso vem desde pequeno e aí, vai ficando mais velho, vai agravando mais. Muitas vezes eu tô doente e não consigo trabalhar, vai cada vez mais nervoso; por exemplo, esses dias nós trabalhamos lá no Alemão, ganhei 130 pilas, ali adiante eu caí, só chegamo em casa e tive que gastar aquele dinheirinho pra me levarem no médico, aí já não sobra, o dinheiro só chegou e saiu (F81, SV inferior).

Observa-se nesse depoimento que, apesar de o entrevistado conviver, desde a infância, com uma doença, sente que na medida em que envelhece ela vai se agravando, pois não consegue trabalhar; além disso, o dinheiro que ganha mal dá para cobrir os gastos do atendimento médico.

As perdas ao longo da vida, para quem convive com uma doença crônica, em especial a classe de trabalhadores rurais, são sentidas por meio das oportunidades perdidas de trabalho. O entrevistado relatou também a dificuldade em conseguir trabalho, pois teve vários 'ataques' durante a atividade, fato esse que inibiu os empregadores, temendo serem responsabilizados por essas ocorrências. Assim, esse cenário apresentado pelo entrevistado de falta de trabalho e gastos financeiros, em momentos de crise, na procura de atendimento, o deixa cada vez mais nervoso. Além disso, devido a sua recorrência ao serviço de saúde de pronto atendimento, alguns profissionais o atendem com desrespeito, afirmando que ele deve procurar outro serviço.

Compreende-se que a experiência de adoecimento se estabelece a partir da situação de vida, que é enunciada pela interação das condições materiais, presentes na oportunidade de trabalho e acesso a bens duráveis; e pela imaterialidade, referente às concepções e desejos, sendo que essa ocorre tanto na dimensão individual como na coletiva e remete à dinâmica de múl- 
tiplos fatores mobilizados como recursos para contornar ou desativar os eventos negativos do cotidiano (Gerhardt e Lopes, 2008).

A interação entre materialidade e imaterialidade é constante, explicitamente na área da saúde, em que o corpo individual se torna social mediante as concepções e os desejos; portanto, é preciso que se desperte para uma, sem desprezar a outra, pois o indivíduo necessita tanto do material quanto do imaterial, seja para sua reprodução física ou social.

\section{Alternância de estado: "tem dias que eu acho que não estou normal, tem dias que eu acho que estou com boa saúde"}

Ao considerar a complexidade da definição de saúde, Gerhardt e Lopes (2008) incluem as percepções das pessoas em relação ao seu estado, nos processos de adoecer e ser saudável. Assim, não há uma estabilidade, há disposição de se adequarem às variações orgânicas, ao meio, à realização de desejos e à liberdade de agir individual e coletivamente no sentido da autopromoção de bem-estar (Gerhardt e Lopes, 2008).

Para Dejours (1986), saúde não é sinônimo de um estado de estabilidade, mas algo que se alterna o tempo todo; é um assunto ligado às próprias pessoas, em seus meios de traçar um caminho em direção ao bem-estar físico, mental e social.

Nesse sentido, ter saúde passa por essa experimentação de incertezas e oscilações, conforme o depoimento a seguir:

Tem dias que eu acho que não tô normal, tem dias que eu acho que tô com boa saúde, não sei porque, se é dos nervos se não é, tem dias que eu digo se morresse era negócio, tem dias que o cara tá mais alegre, mais animado (...) e assim vai levando a vida, um dia sim, um dia não, não sei se o cara tem um problema e não sabe, ou não tem (F156, SV superior).

Observa-se certa desconfiança nesse sentimento de instabilidade, e a entrevistada indaga: "será que é dos nervos?". Pois, por dias não se sente bem, acha que "não está normal", como ela denomina, e se morresse era até "um bom negócio"; no entanto, em outros, se acha com boa saúde, alegre e mais animada. Dessa maneira, vai levando a vida, mas sua desconfiança persiste: "será que se tem um problema e não [se] sabe?".

O mito da saúde perfeita e bem-estar completo é um desejo inatingível, pois até mesmo fisiologicamente o organismo humano está ininterruptamente operando mudanças, seja durante o sono e vigília, no crescimento ou no envelhecimento; da mesma forma, os sentimentos também não são 
estanques, a alegria, assim como a angústia são alternadas nas sensações diárias (Dejours, 1986).

As falas a seguir ilustram esse sentimento de viver a instabilidade orgânica:

Para mim raramente alguém é curado de um tudo, porque até um resfriado ou uma gripe podem acabar matando, pode acontecer uma coisa grave, e muitas vezes acontece, tem quem diga, quem tem saúde tem tudo, mas eu não vi até hoje alguém ter completa saúde; se tem, eu queria saber quem vive tão tranquilo que não tenha nada (F30, SV médio).

Se eu disse que não tenho saúde, eu tava mentindo, e se dissesse que sou uma pessoa doente, também taria mentindo; pra mim tô independente como uma outra pessoa, quem não consegue se mexer tá completamente doente, ou tem que esperar por outra pessoa; nesse sentido que essa é a verdadeira pessoa doente, a pessoa que tem um escape ela não tá completamente doente, tá em cima do muro, não tá nem doente, nem não doente (F19, SV inferior).

Na primeira fala, o entrevistado constata que, até hoje, não viu alguém ter saúde completa, pois "raramente se é curado de um tudo, um simples resfriado pode se agravar", além disso, as 'intranquilidades' da vida não permitem ter uma saúde completa e questiona, "quem vive tão tranquilo que não tenha (ou sinta) nada"?

Na segunda fala, o entrevistado encontra-se 'em cima do muro', em que de um lado está a saúde e, de outro, a doença; é possível que, em alguns momentos, incline-se mais para um lado, ora para outro, porém, mantém-se em cima do muro, entre esses dois estados. E prossegue sua ideia de quem ele considera 'verdadeiramente' doente: é aquele que não tem autonomia, que se acha imobilizado. Essa imobilização, apesar de ser referida no sentido do movimento físico, também serve para reflexão da imobilização da ação subjetiva, quando mesmo tendo os movimentos físicos a pessoa não consegue mobilizar recursos, seja para sua reprodução física ou social.

Nesse sentido, observam-se quão múltiplos são os laços, por vezes invisíveis, que demarcam uma sociedade, no estabelecimento de contratos, confianças, medo e amizade, os quais interagem com relações macroestruturais e microestruturais: no primeiro caso, com as políticas públicas e condições de vida, dentre outras; e, no segundo, referem-se à maneira de como o indivíduo as operacionaliza no dia-a-dia.

Assim, as explicações para as experiências pessoais, dentre elas a saúde e a doença, combinam a relação entre o individual e o coletivo, o material e o imaterial, que precisam ser levados em conta para promover essas formas de saúde, tanto no nível de elaboração de políticas, como na execução nos serviços (Gerhardt e Lopes, 2008; Coelho e Almeida Filho, 2002). 
Portanto, as explicações acionadas para compreender um determinado fenômeno mediaram as práticas adotadas:

Tem muita saúde, depois não tem saúde, aí tem tratamento, tem isso e aquele outro, muitas vezes nem tem tratamento, aí já passa a viver o outro lado, né, ter mais preocupação, sei lá eu, pega a pensar mais coisa, a imaginar mais coisa (F156, SV superior).

Permanece nesse depoimento a noção de instabilidade no estado de saúde. Primeiro tem-se muita saúde, depois não se tem, então se passa a viver o outro lado. Tal concepção demonstra a proximidade e, ao mesmo tempo, a diferença de sentimentos, pois, com a perda da saúde, passa-se a viver mais preocupação e a imaginar situações desagradáveis.

A experiência da doença constitui uma preocupação em reconstruir e negociar significados mediante as dificuldades imputadas por ela, assim como elaborar estratégias que ajudem a (re)situar-se no mundo social (Alves e Rabelo, 1998).

Dessa forma, a aproximação das concepções de saúde e doença, exemplificadas na alternância do estado de saúde e doença, reflete a combinação do contexto de vida, histórico e social de uma comunidade rural que, cotidianamente, experimenta os desafios do meio (natureza), muitas vezes a penúria financeira e os limites do corpo, mas que nutre motivações, tanto conscientes como inconscientes de 'ter um bom viver'.

Apesar das três diferentes 'situações de vida' representadas pelas condições de vida e mobilização de recursos sociais, não se encontrou incongruência entre as concepções, indicando que essas não são determinadas isoladamente pelas condições socioeconômicas, mas pela interação dessas características com a matriz histórica e cultural local.

\section{Considerações finais}

A saúde e a doença para os sujeitos dessa pesquisa formavam um construto social que incluía dimensões físicas e subjetivas, por meio de rupturas e formação de identidade. As concepções biológicas incorporaram conceitos de doenças com seus parâmetros biomédicos e de enfermidade, como um processo vivido no cotidiano individual e coletivo. Nesse cotidiano, as condições de vida expressas, como ter 'boa moradia', acesso à alimentação e água, foram aspectos materiais relevantes, mas não determinantes da saúde e da doença, pois evidenciou-se nas estratégias pessoais e coletivas a busca de elementos imateriais, como alegria, prazer e distração em conversar com amigos e vizinhos, maneiras de ter ou preservar a saúde. 
O sentimento em relação ao estado de saúde independe da presença de uma doença, pois, apesar de conviver com seu aspecto crônico, as pessoas se consideram saudáveis, substituindo atividades de trabalho anteriormente exercidas por outras que consigam desempenhar. No entanto, a sensação de estar adoecido é fortemente vinculada ao modo como se vivencia essa enfermidade, assim como ao sofrimento dela decorrente, tendo em vista a incapacidade que este estado impõe, seja física ou mental. A alternância entre sentir-se doente ou saudável vem da constatação prática de que nenhum estado é contínuo: ele pode se modificar, como igualmente o dia e a noite, o sol e a chuva. Portanto, a observação do meio natural sinaliza o quão tênue são os estados de saúde e doença.

A 'situação de vida', elaborada a partir das condições de vida e mobilização de recursos sociais, demonstrou que, apesar das diferenças econômicas, esse grupo apresentava uma coesão social, especialmente em sua matriz cultural de trabalhadores rurais. O valor simbólico atribuído ao trabalho remete à ideia de ser útil à sociedade e de inserção na cadeia produtiva, mas essa atividade pode prejudicar o trabalhador, contribuindo para seu adoecimento.

Enfatiza-se, assim, a necessidade de considerar o significado do fenômeno saúde e doença como ferramenta imprescindível para a formulação de programas de promoção e prevenção à saúde da população, em especial a rural, devido às suas dificuldades funcionais, geográficas e culturais em acessar serviços.

\section{Nota do Editor}

Este artigo é parte da dissertação de mestrado A outra face dos determinantes sociais de saúde: subjetividades na construção do cotidiano individual e coletivo em uma comunidade rural, de Deise Lisboa Riquinho, defendida em 2009 na Universidade Federal do Rio Grande do Sul. A pesquisa que deu origem à dissertação recebeu financiamento conforme o Edital n. 026/2006 $\mathrm{MCT} / \mathrm{CNPq}$ /MS-SCTIE-Decit. 


\section{Notas}

1 Bolsista do Conselho Nacional de Desenvolvimento Científico e Tecnológico (CNPq). Doutoranda em Saúde Pública pela Escola Nacional de Saúde Pública, Fundação Oswaldo Cruz (Ensp/Fiocruz), Rio de Janeiro, Brasil. <deiselis@terra.com.br> Correspondência: Rua Giordano Bruno, 271/04, Rio Branco, Porto Alegre, Rio Grande do Sul, CEP 90420-150.

2 Professora adjunta de Saúde Coletiva da Escola de Enfermagem da Universidade Federal do Rio Grande do Sul, Porto Alegre, Brasil. Doutora em Antropologia Social pela Université de Bordeaux 2, França. <tatiana.gerhardt@ufrgs.br>

\section{Referências}

ADORNO, Rubens de Camargo Ferreira et al. Mulher, muler: saúde, trabalho, cotidiano. In: ALVES, Paulo César; MINAYO, Maria Cecília de Souza (Org.). Saúde e doença: um olhar antropológico. Rio de Janeiro: Fiocruz, 1994. p. 141-152.

ALVES, Paulo César; RABELO, Miriam Cristina. Repensando os estudos sobre as representações e práticas em saúde/doença. In: ALVES, Paulo César; RABELO, Miriam Cristina (Org.). Antropologia da saúde: traçando identidades e explorando fronteiras. Rio de Janeiro: Fiocruz; Relume Dumará, 1998. p.107-122.

ARENDT, Hannah. A condição humana. 10. ed. Rio de Janeiro: Forense Universitária, 2008.

AYRES, José Ricardo. Epidemiologia, promoção da saúde e o paradoxo do risco. Revista Brasileira de Epidemiologia, São Paulo, v. 5, supl. 1, p. 28-42, 2002.

Uma concepção hermenêutica de saúde. Physis: Revista de Saúde Coletiva, Rio de Janeiro, v. 17, n. 1, p. 43-62, 2007.
BARSAGLINI, Reni Aparecida. O viver com diabetes. In: CANESQUI, Ana Maria. (Org.). Olhares socioantropológicos sobre os adoecimentos crônicos. São Paulo: Hucitec, 2007. p. 53-85.

BOLTANSKI, Luc. As classes sociais e o corpo. 3. ed. Rio de Janeiro: Graal, 1989.

COELHO, Maria Thereza Ávila Dantas; ALMEIDA FILHO, Naomar de. Conceitos de saúde em discursos contemporâneos de referência científica. História, Ciências, Saúde - Manguinhos, Rio de Janeiro, v. 9, n. 2. p. 315-333, 2002.

\section{COMISSION ON SOCIAL DETERMINANTS} OF HEALTH (CSDH). 2005. A conceptual framework for action on social determinants of health. Disponível em: <www.determinantes. fiocruz.br>. Acesso em: 15 mar. 2007.

CONSELHO NACIONAL DE SAÚDE (Brasil). Oitava Conferência Nacional de Saúde. Relatório final. Brasília, 1986. Disponível em: $<$ www.conselho.saúde.gov.br/biblioteca/ Relatorios.htm>. Acesso em: 25 nov. 2007. 
CORBIN, Juliet. The Body in Health and Illness. Qualitative Health Research, v. 13, n. 2, p. 256-267, 2003.

DEJOURS, Christophe. Por um novo conceito de saúde. Revista Brasileira de Saúde Ocupacional, São Paulo, v. 14, n. 54, p. 7-11, 1986.

DIAS, Glauce et al. A vida nos olhos, o coração nas mãos: concepções e representações femininas do processo saúde-doença. História, Ciências, Saúde-Manguinhos, Rio de Janeiro, v. 14, n. 3, p. 779-800, 2007.

FAVORETO, Cesar Augusto Orazem; CABRAL, Cristiane Coelho. Narrativas sobre o processo saúde-doença: experiências em grupos operativos de educação em saúde. Interface: Comunicação, Saúde, Educação, Botucatu, v. 13, n. 28 , p. $7-18,2009$.

FIALHO, Marco Antônio Verardi. Rincões de pobreza e desenvolvimento: interpretações sobre comportamento coletivo. 2005. $213 \mathrm{f}$. Tese (Doutorado em Sociologia Rural). Instituto de Ciências Humanas e Socias - Curso de Pós-graduação em Desenvolvimento, Agricultura e Sociedade, Universidade Federal do Rio de Janeiro, 2005.

GERHARDT, Tatiana Engel. Anthropologie et santé publique: approche interdisciplinaire - pauvreté, situations de vie et santé au quotidien à Paranaguá, Paraná, Brésil. 2000. 362 f. Tese (Docteur en Ethnologie, option Anthropologie sociale et culturelle) - Université de Bordeaux 2. Bordeaux, 2000.

. Itinerários terapêuticos e suas múltiplas dimensões: desafios para a prática da integralidade e do cuidado como valor. In: PINHEIRO, Roseni; MATTOS, Rubem Araújo de. (Org.). Razões públicas para a integralidade em saúde: o cuidado como valor. Rio de Janeiro: Cepesc/Uerj, Abrasco, 2007. 401 p. p. 279-300.

GERHARDT, Tatiana Engel; LOPES, Marta Júlia Marques. Desigualdades sociais e de saúde: elementos para análise interdisciplinar. Porto Alegre, 2008. Texto não publicado.
GHIGLIONE, Rodolphe; MATALON, Benjamim. O inquérito: teoria e prática. 3 ed. Portugal: Celta, 1997.

HEGEL, Georg Wilhelm Friedrich. A fenomenologia do espírito. Petrópolis: Vozes, 1992.

HELLER, Agnes. O cotidiano e a história. 8 ed. São Paulo: Paz e Terra, 2008.

HELMAN, Cecil. Cultura, saúde e doença. 4. ed. Porto Alegre: Artmed, 2003.

HERZLICH, Claudine. Saúde e doença no início do século XXI: entre a experiência privada e a esfera pública. Physis: Revista de Saúde Coletiva, v. 14, n. 2, p. 383-394, 2004

IBGE. Censo demográfico 2000: resultados da amostra. Rio de Janeiro: IBGE, 2002.

FIGUEIRA, Tais Rocha et al. Percepções e ações de mulheres em relação à prevenção e promoção da saúde na atenção básica. Revista de Saúde Pública, São Paulo, v. 43, n. 6, p. 937-43, 2009.

MELO, Elza Machado de. Ação comunicativa, democracia e saúde. Ciência \& Saúde Coletiva, Rio de Janeiro, v. 10, supl., p. 167178, 2005.

MINAYO, Maria Cecília de Souza. Conceitos de avaliação por triangulação de métodos. In: MINAYO, Maria Cecília de Souza; ASSIS, Simone Gonçalves de; SOUZA, Edinilsa de Souza (Org.). Avaliação por triangulação de métodos: abordagens de programas sociais. Rio de Janeiro: Editora Fiocruz, 2005. p. 19-51.

O desafio do conhecimento: pesquisa qualitativa em saúde. 10. ed. São Paulo: Hucitec, 2007.

RAYNAUT, Claude. Interfaces entre a antropología e a saúde: em busca de novas abordagens conceituais. Revista Gaúcha de Enfermagem, Porto Alegre, v. 27, n. 2, p. 149165,2006

RIQUINHO, Deise Lisboa. A outra face dos determinantes sociais de saúde: subjetividades 
na construção do cotidiano individual e coletivo em uma comunidade rural. 212 f. Dissertação (Mestrado em Enfermagem) - Escola de Enfermagem da Universidade Federal do Rio Grande do Sul, Porto Alegre, 2009.

SCHNEIDER, Sergio; FIALHO, Marco Antônio Verardi. Pobreza rural, desequilíbrios regionais e desenvolvimento agrário no Rio Grande do Sul. Teoria e Evidência Econômica, Passo Fundo, v. 8, n. 15, p. 117-149, 2000.

SOARES, Jussara Calmon Reis de Souza; CAMARGO JR., Kenneth Rochel. A autonomia do paciente no processo terapêutico como valor para a saúde. Interface: Comunicação, Saúde, Educação, v. 11, n. 21, p. 65-78, 2007.

SOUZA, Aline Corrêa de. Como manda o figurino: práticas entre idosos de Porto Alegre. 2005. 116 f. Dissertação (Mestrado em Enfermagem) - Escola de Enfermagem da Universidade Federal do Rio Grande do Sul, Porto Alegre, 2005.

STOTZ, Eduardo Navarro. Necessidades de saúde: mediações de um conceito (contribuições das Ciências Sociais para a fundamentação teórico-metodológica de conceitos operacionais da área de planejamento em saúde). 1991. 765f. Tese (Doutorado em Saúde Pública) - Escola Nacional de Saúde Pública, Rio de Janeiro, 1991.

THEME FILHA, Mariza Miranda; SZWARCWALD, Célia Landmann; SOUZA JUNIOR, Paulo Roberto Borges de. Medidas de morbidade referida e inter-relações com dimensões de saúde. Revista de Saúde Pública, São Paulo, v. 42, n. 1, p. 73-81, 2008.

VALLA, Victor V. Globalização, a questão social e a nova pobreza. In: VALLA, Victor V.; STOTZ, Eduardo Navarro; ALGEBAILE, Eveline Bertino (Org.). Para compreender a pobreza no Brasil. Rio de Janeiro: Contraponto; Escola Nacional de Saúde Pública, 2005. p. 33-52.

VIACAVA, Francisco. Informações em saúde: a importância dos inquéritos populacionais. Ciência \& Saúde Coletiva, Rio de Janeiro, v. 7, n. 4, p. 607-621, 2002.

Recebido em 16/03/2010

Aprovado em 08/07/2010 